\title{
Compound Identification of Selected Rose Species and Cultivars: an Insight to Petal and Leaf Phenolic Profiles
}

\author{
Vlasta Cunja ${ }^{1}$, Maja Mikulic-Petkovsek, Franci Stampar, and Valentina Schmitzer \\ University of Ljubljana, Biotechnical Faculty, Department of Agronomy, Chair for Fruit, Wine and \\ Vegetable Growing, Jamnikarjeva 101, SI-1000 Ljubljana, Slovenia
}

\begin{abstract}
AdDitional INDEX wORDs. anthocyanins, flavanols, flavonols, hydrolysable tannins, phenolic acids, Rosa
ABstract. Using high-performance liquid chromatography/mass spectrometry, leaf and petal phenolic profiles of four rose (Rosa) species ( $R$. canina, $R$. glauca, $R$. rubiginosa, $R$. sempervirens) traditionally used for medicinal purposes and three modern rose cultivars (Rosarium Uetersen, Ulrich Brunner Fils, Schwanensee) were determined. An abundance of phenolic constituents was identified: seven different anthocyanins and 31 flavonols in petals; 30 flavonols, 14 phenolic acids, and their derivatives; 15 flavanols; and 20 hydrolysable tannins in leaves. Additionally, petal color was measured with a colorimeter and regression analysis indicated a strong correlation between color parameter $a^{*}$ and total anthocyanin content. The content and composition of phenolic compounds varied significantly among species and cultivars and plant organs investigated. Distinct differences in the distribution of leaf phenolic compounds were observed, especially between Rosa species and modern rose cultivars. In general, leaves of analyzed species were richer in content of most phenolic groups and individual components compared with cultivars. Multivariate statistical analysis clustered the investigated species and cultivars into three distinct groups. Among species, leaves of $R$. canina stood out with their high and varied phenolic content. Conversely, leaves of the susceptible cultivar Schwanensee appeared most dissimilar as a result of their low levels of phenolic constituents.
\end{abstract}

The genus Rosa contains more than 200 species distributed in Europe, Asia, the Middle East, and North America (Li et al., 2013). The genus is represented by 22 species in the Slovenian flora, among which $R$. canina, $R$. glauca, $R$. rubiginosa, and $R$. sempervirens are most frequent (Martincic et al., 1999). Numerous rose cultivars are widely planted in gardens and parks for their aesthetic value and native plants are harvested for their fruit and flowers.

Medicinal benefits of the genus Rosa have been reported in many studies and specific plant tissue has been used for different purposes (Nowak and Gawlik-Dziki, 2007). Rose hips comprise several biologically active compounds and are famous for their high content of vitamins, particularly vitamin C (Hvattum, 2002; Roman et al., 2013). Fragrance compounds in rose petals are praised in perfumery and food industries (Farooq et al., 2012). Similarly, rose leaves have been used in Chinese and European medicine for centuries as ingredients in common cold remedies (Coruh and Ercisli, 2010; Fenglin et al., 2004). Health-beneficial properties of Rosa leaves may be attributed to their content of phenolics, which are known to possess a wide spectrum of bioactive functions such as antioxidant and antiinflammatory effects (Sroka, 2005). Interspecific variation in the levels of bioactive compounds and their healing potential led to selective harvest of specific rose species for traditional uses. In Slovenia, hips, petals, and leaves of $R$. canina have

Received for publication 22 Nov. 2013. Accepted for publication 19 Dec. 2013. This work is part of the program Horticulture No P4-0013-0481 funded by the Slovenian Research Agency.

We give special thanks to Dr. Joze Bavcon and Matjaz Mastnak of the Botanical Garden and Arboretum Ljubljana for providing rose samples and many useful information. The work was reviewed by two internal reviewers from the field of study, Dr. Gregor Osterc and Dr. Robert Veberic.

${ }^{1}$ Corresponding author. E-mail: vlasta.cunja@bf.uni-lj.si. been favored for their healing powers, but other indigenous rose species have not been used to the same extent.

A number of studies have been published on the phenolic and mineral composition of rose hips in connection to their antioxidant activity (Ghazghazi et al., 2012; Hvattum, 2002; Roman et al., 2013). Petal phenolic antioxidants have also been identified in several rose species and cultivars (Biolley et al., 1994; Cai et al., 2005; Mikanagi et al., 1995; Schmitzer et al., $2010,2012)$. However, research on rose leaf polyphenols is still partial and scarce. Different authors report total phenolic content, total flavonoid, or total flavonol aglycone levels in leaf extracts (Ghazghazi et al., 2012; Nowak and Gawlik-Dziki, 2007) of Rosa species, but studies targeted at identification of individual phenolic compounds are limited.

The aim of the present study was to identify and quantify phenolic compounds in petals of several indigenous rose species in Slovenia and compare them with the phenolic profiles of certain modern rose cultivars. Moreover, rose leaf phenolic profiles were established and individual phenolic compounds have been identified and quantified for the first time in selected rose species. The qualitative and quantitative differences in leaf phenolic compounds among analyzed rose species and cultivars are discussed.

\section{Materials and Methods}

Plant material. Four rose species: $R$. glauca (pink flowers), R. canina ssp. canina (white to pale pink flowers), R. sempervirens (white flowers), and R. rubiginosa (pink flowers), and three cultivars: Rosarium Uetersen, Ulrich Brunner Fils (both with pink flowers), and Schwanensee (white flowers with light pink center), were selected for the study. Plants were located at the Botanical Garden and Arboretum Ljubljana (lat. $46.18^{\circ} \mathrm{N}$, 
long. $14.61^{\circ} \mathrm{E}$, altitude $250 \mathrm{~m}$ ) and leaves and petals for the analysis were sampled in June 2013. Flowers were collected and analyzed in developmental stage fully open flower (Schmitzer et al., 2010) and petal color measurements were recorded. Leaves were collected at their mature stage and only the first three fully expanded leaves on the branch were analyzed. Plant material was frozen in liquid nitrogen and stored at $-20{ }^{\circ} \mathrm{C}$ until further analysis.

Petal color measurements. Flower color was measured by a portable colorimeter (CR-10 Chroma; Minolta, Osaka, Japan) with $\mathrm{C}$ illuminant. The colorimeter was calibrated with a white standard calibration plate before use. In the CIE $L^{*} a * b^{*}$ system of color representation, the $L^{*}$ value corresponds to a dark-bright scale and represents the relative lightness with a range from 0 to $100(0=$ black, $100=$ white $)$. Color parameters $a^{*}$ and $b^{*}$ extend from -60 to $60 ; a^{*}$ negative is for green and $a^{*}$ positive is for red and $b^{*}$ negative is for blue and positive for yellow. The hue angle $\left(h^{\circ}\right)$ is expressed in degrees from 0 to 360 , where $0^{\circ}=$ red, $90^{\circ}=$ yellow, $180^{\circ}=$ green, and $270^{\circ}=$ blue. Color was measured in the middle of each petal (three replicates per flower; 10 flowers per repetition) to ensure equal measurement conditions.

EXTRACTION AND HIGH-PERFORMANCE LIQUID CHROMATOGRAPHY DETERMINATION OF PHENOLIC COMPOUNDS. Flower petals (combined samples consisting of five to 15 flowers) and leaves (combined samples consisting of 10 leaves) were ground to a fine powder with liquid nitrogen and $1 \mathrm{~g}$ of powder was extracted with $6 \mathrm{~mL}$ methanol containing 3\% (v/v) formic acid and 1\%(w/v) 2,6-Di-tert-butyl-4-methylphenol (BHT) in an ultrasonic bath for $1 \mathrm{~h}$. Samples were centrifuged for $7 \mathrm{~min}$ at $12,000 \mathrm{~g}_{\mathrm{n}}$. Supernatant was filtered through a polyamide filter (Chromafil AO-20/25; Macherey-Nagel, Düren, Germany) and transferred to a vial before injection into the high-performance liquid chromatography (HPLC) system. Samples were analyzed using a Thermo Finnigan Surveyor HPLC system (Thermo Scientific, San Jose, CA) with a diode array detector at $280 \mathrm{~nm}$ (phenolic acids and their derivatives, hydrolysable tannins, flavanols), $350 \mathrm{~nm}$ (glycosides of quercetin, kaempferol, myricetin, and isorhamnetin), and $530 \mathrm{~nm}$ (anthocyanins). A HPLC column $(150 \times 4.6 \mathrm{~mm}$, Gemini $3 \mu \mathrm{m}$ C18; Phenomenex, Torrance, CA) protected with a Phenomenex security guard column operated at $25^{\circ} \mathrm{C}$ was used. The injection volume was $20 \mu \mathrm{L}$ and the flow rate maintained at $0.6 \mathrm{~mL} \cdot \mathrm{min}^{-1}$. The elution solvents were aqueous $0.1 \%$ formic acid in double-distilled water (A) and $0.1 \%$ formic acid in acetonitrile (B). Samples were eluted according to the linear gradient from $5 \%$ to $20 \% \mathrm{~B}$ in the first 15 min followed by a linear gradient from $20 \%$ to $30 \%$ B for $5 \mathrm{~min}$, then an isocratic mixture for $5 \mathrm{~min}$, followed by a linear gradient from $30 \%$ to $90 \% \mathrm{~B}$ for $5 \mathrm{~min}$, and then an isocratic mixture for $15 \mathrm{~min}$ before returning to the initial conditions (Wang et al., 2002). Phenolics were further identified using a mass spectrometer (LCQ Deca XP MAX; Thermo Scientific) with an electrospray ionization interface operating in negative/ positive ion mode using multiple-stage mass spectrometry $\left(\mathrm{MS}^{n}\right)$ scanning mode from $\mathrm{m} / \mathrm{z} 115$ to 1500 . The injection volume was $10 \mu \mathrm{L}$ and the flow rate maintained at $0.6 \mathrm{~mL} \cdot \mathrm{min}^{-1}$. Capillary temperature was $250{ }^{\circ} \mathrm{C}$, the sheath gas and auxiliary gas were 20 and 8 units, respectively, and the source voltage was $4 \mathrm{kV}$ for negative ionization and $0.1 \mathrm{kV}$ for positive ionization. Spectral data were elaborated using Excalibur software (Thermo Scientific). The identification of compounds was confirmed by comparing retention times and their spectra as well as by adding the standard solution to the sample and by fragmentation. The content of phenolic compounds was assessed from peak areas and quantified with the use of corresponding external standards. For compounds lacking standards, quantification was carried out using similar compounds as standards. Thus, galloylquinic acid, methyl gallate hexoside, digalloyl quinic acid, trigalloyl hexose, digalloyl pentose, ellagic acid hexoside, digalloyl glucose isomer, vescalagin, and compounds with a hexahydroxydiphenic (HHDP) moiety were quantified with the calibration curve of ellagic acid, $p$-coumaric acid hexoside, $c i s$ - and trans-5-O-p-coumaroylquinic acid by $p$-coumaric acid, caffeoyl hexose by caffeic acid, sinapic acid hexoside by sinapic acid, all procyanidins by the standard curve of procyanidin B2, all kaempferol compounds by kaempferol3-glucoside, and quercetin (Q) compounds (except Q-rutinoside, Q-galactoside, Q-glucoside, Q-rhamnoside, Q-arabinofuranoside, and Q-xyloside) by quercetin-3-galactoside. Anthocyanins were quantified with the standard curves of cyanidin-3glucoside, pelargonidin-3-glucoside, and peonidin-3-glucoside, respectively. Total anthocyanins, total quercetin and kaempferol glycosides, total flavonols, total phenolic acids, hydrolysable tannins, and flavanols were calculated as the sum of all identified phenolics of the group. All compounds were expressed on a fresh weight basis in micrograms per gram.

Chemicals. The standards used to determine the phenolic compounds in samples were caffeic, ellagic, sinapic and chlorogenic acid (5-caffeoylquinic acid), quercetin-3- $O$-rutinoside, cyanidin-3-O-glucoside, pelargonidin-3-O-glucoside, and peonidin-3-O-glucoside from Sigma-Aldrich (Steinheim, Germany); and $(+)$-epicatechin, $p$-coumaric acid, procyanidin B2, kaempferol-3- $O$-glucoside, quercetin-3- $O$-glucoside, quercetin-3-O-xyloside, quercetin-3-O-arabinofuranoside, quercetin-3-O-galactoside, and quercetin-3- $O$-rhamnoside from Fluka (Buchs, Switzerland). The chemicals for the sample preparation and mobile phases were methanol, BHT, and acetonitrile from Sigma-Aldrich and formic acid from Fluka. The water used in mobile phase was bidistilled and purified with a Milli-Q water purification system by Millipore (Bedford, MA).

Statistical analysis. The results were analyzed using Statgraphics Plus 4.0 (Manugistics, Rockville, MD) program using one-way analysis of variance. Differences in phenolic content between species/cultivars were estimated with Duncan's multiple range test between means $(P<0.05)$. Multiplevariable analysis with Pearson's correlation coefficient $(r)$ was calculated between color variables $a^{*}, L^{*}$, and $\mathrm{C}$ and total and individual anthocyanin content at $P<0.05$. Multivariate statistical analysis (hierarchical cluster analysis, discriminate analysis, and classification) was conducted to interpret the differences in secondary metabolites among species and cultivars.

\section{Results and Discussion}

Petal color measurements. Color parameter $a^{*}$ represents the amount of red coloration of plant tissue (Lancaster et al., 1997) and thus increases from white to reddish colored petals. Highest values were measured on the surface of the 'Ulrich Brunner Fils' and 'Rosarium Uetersen' and $R$. glauca petals and lowest on $R$. sempervirens petals (Table 1). Values of color parameter $b^{*}$, which indicates yellow (positive values) and blue hues (negative values) (Lancaster et al., 1997), were higher in species and cultivars with (predominantly) white petals (R. sempervirens, R. canina, and 'Schwanensee') and lower 


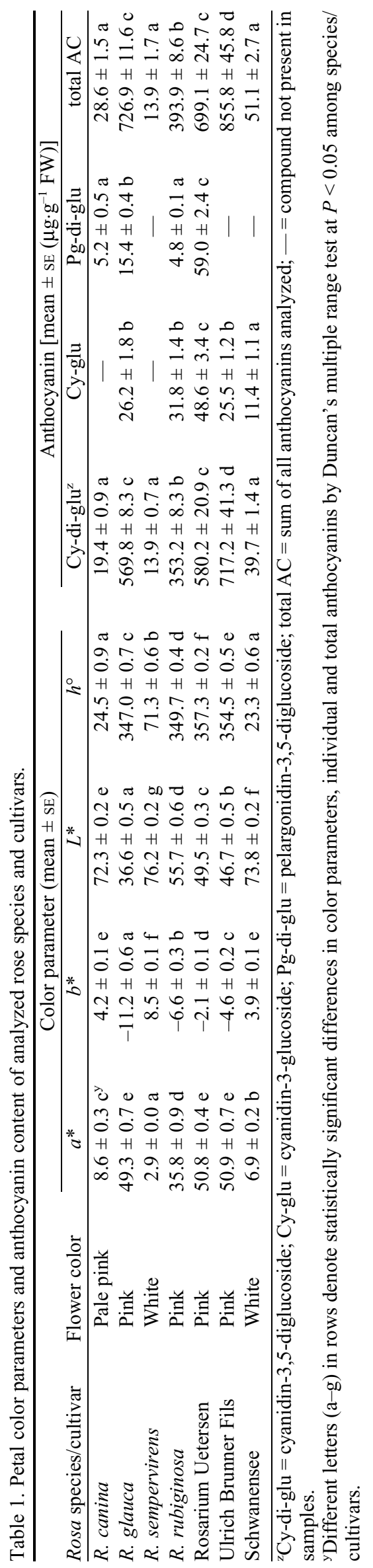

in pink-flowered species and cultivars ( $R$. glauca, $R$. rubiginosa, and 'Ulrich Brunner Fils'). An inverse relationship between the parameters $a^{*}$ and $b^{*}$ was also observed in previous research when comparing flowers of different cultivars of groundcover rose (Schmitzer et al., 2010). Analysis of lightness coefficient $\left(L^{*}\right)$ and hue angle $\left(h^{\circ}\right)$ similarly revealed statistically significant differences among studied species and cultivars. The highest values of parameter $L^{*}$ were observed in flowers of species and cultivars associated with highest $a^{*}$ value and lowest $b^{*}$ value ( $R$. sempervirens, $R$. canina, and 'Schwanensee'). Flower petals of the latter were also characterized by lowest values of the $h^{\circ}$ parameter.

Anthocyanins ANd flavonols in rose petals. Anthocyanins are the principal pigments in rose petals attributing intense red to mauve color hues. Flower color investigation of roses so far has shown that four major anthocyanins, 3-glucosides and 3,5-diglucosides of cyanidin (Cy) and peonidin (Pn) can be detected in flowers of wild Rosa species and also pelargonidin (Pg) 3-glucoside and Pg-3,5-diglucoside in Rosa cultivars (Biolley et al., 1994; Kumar et al., 2008; Mikanagi et al., 1995, 2000). Rarely, Pg-based anthocyanins can be accumulated in Rosa plant parts (Cai et al., 2005; Eugster and Märki-Fischer, 1991). In this study two major anthocyanins have been identified in analyzed rose petals, namely Cy-3,5-diglucoside and Cy-3-glucoside [Table 1 (only major anthocyanins presented)], which is in accordance with our earlier studies (Schmitzer et al., 2010). Additionally, Cy-3-rutinoside, Pg-3,5diglucoside, Pg-3-glucoside, Pn-3,5-diglucoside, and Pn-3glucoside have been confirmed in petals of specific Rosa species or cultivars (Table 2), but their content only accounted several percent of total anthocyanin content level (data not shown). Occurrence of cyanidin, pelargonidin, and peonidinbased anthocyanins has been reported in different red rose cultivars (Biolley et al., 1994; Mikanagi et al., 2000) and higher levels of Cy-3,5-diglucoside quantified in analyzed rose species and cultivars are in agreement with the reported color expression of cyanidins, generally contributing to more intense red hues of plant tissue (Tatsuzawa et al., 2012). Significant differences in anthocyanin composition and content were determined among roses analyzed (Table 1). Highest levels of Cy-3,5-diglucoside, Cy-3-glucoside, and consequently total anthocyanins were quantified in pink-flowering species and cultivars ( $R$. glauca, 'Ulrich Brunner Fils', and 'Rosarium Uetersen'). Although the petals of 'Ulrich Brunner Fils' were characterized by highest levels of total anthocyanins, they only accumulated three anthocyanin glycosides compared with the petals of 'Rosarium Uetersen' in which five anthocyanins have been identified. Anthocyanin composition is in tight connection with color expression (Lancaster et al., 1997; Schmitzer et al., 2009) and regression analysis indicated a strong correlation between color parameter $a^{*}$ and total anthocyanin content (Pearson's correlation coefficient $=0.97, r^{2}=94.9 \%$ ), similar to the reports of Schmitzer et al. (2010).

Thirty-one flavonols have been detected in rose petals; their content varied significantly among species and cultivars analyzed. As a result of a similar ultraviolet spectrum of individual components of each phenolic group and limited availability of external standards, HPLC-mass spectroscopy was used for reliable peak identification (Table 2). The presence of seven major Q glycosides (Q-rutinoside, Q-glucoside, Q-glucuronide, Q-arabinofuranoside, Q-galactoside, Q-xyloside, and Q-rhamnoside) and five major kaempferol $(\mathrm{K})$ glycosides (K-diglucoside, 
Table 2. Phenolic compounds in leaves and petals of Rosa species/cultivars, their mass-to-charge ratio $(\mathrm{m} / \mathrm{z})$ values of the molecular masses and main fragments [second- $\left(\mathrm{MS}^{2}\right)$ and third-generation $\left(\mathrm{MS}^{3}\right)$ product ion] in positive $\left([\mathrm{M}-\mathrm{H}]^{+}\right)$, and negative ion mode $\left([\mathrm{M}-\mathrm{H}]^{-}\right)$identified with electrospray ionization mass spectrometry (ESI-MS).

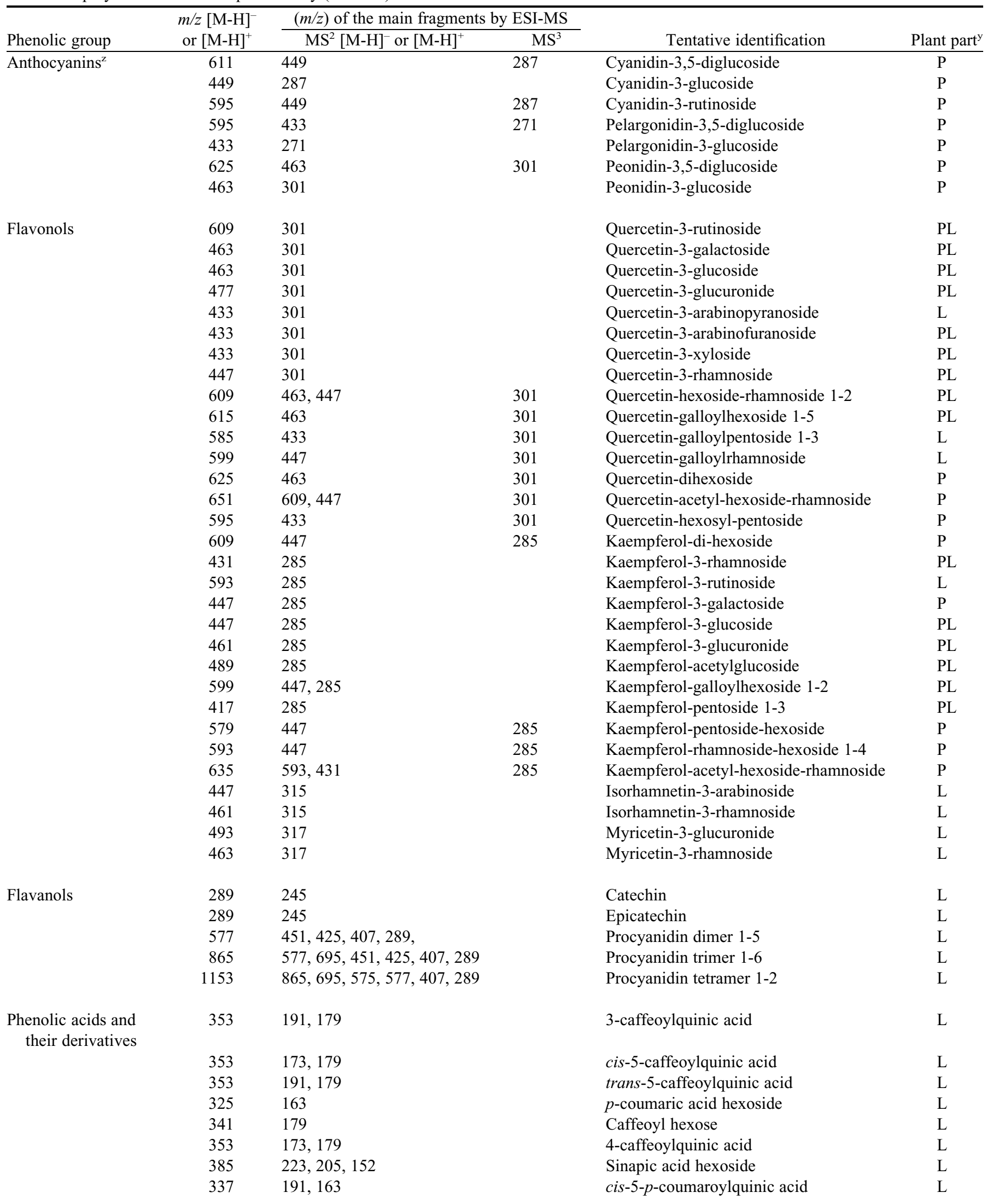


Table 2. Continued.

\begin{tabular}{|c|c|c|c|c|c|}
\hline \multirow[b]{2}{*}{ Phenolic group } & \multirow{2}{*}{$\begin{array}{c}m / z[\mathrm{M}-\mathrm{H}]^{-} \\
\text {or }[\mathrm{M}-\mathrm{H}]^{+}\end{array}$} & \multicolumn{2}{|c|}{$(\mathrm{m} / \mathrm{z})$ of the main fragments by ESI-MS } & \multirow[b]{2}{*}{ Tentative identification } & \multirow[b]{2}{*}{ Plant part ${ }^{\mathrm{y}}$} \\
\hline & & $\mathrm{MS}^{2}[\mathrm{M}-\mathrm{H}]^{-}$or $[\mathrm{M}-\mathrm{H}]^{+}$ & $\mathrm{MS}^{3}$ & & \\
\hline & 337 & 191,163 & & trans-5-p-coumaroylquinic acid & $\mathrm{L}$ \\
\hline & 301 & $257,229,185$ & & Ellagic acid & $\mathrm{L}$ \\
\hline & 345 & 183 & & Methyl gallate hexoside & $\mathrm{L}$ \\
\hline & 463 & 301 & & Ellagic acid hexoside & $\mathrm{L}$ \\
\hline & 433 & 301 & & Ellagic acid pentoside $1-2$ & $\mathrm{~L}$ \\
\hline & 495 & 343 & 191,169 & Digalloyl quinic acid & $\mathrm{L}$ \\
\hline & 635 & $483,465,423,271,193$ & & Trigalloyl hexose $1-2$ & $\mathrm{~L}$ \\
\hline & 453 & $313,327,285,169$ & & Digalloyl pentose & $\mathrm{L}$ \\
\hline & 483 & $439,331,313,271,169$ & 313,287 & Digalloyl glucose isomer & $\mathrm{L}$ \\
\hline & 783 & $481,301,275$ & 257,229 & Di-HHDP glucose 1-2 & $\mathrm{L}$ \\
\hline & 785 & $633,615,419,301,275$ & 257 & HHDP digalloyl glucose isomer 1-3 & $\mathrm{L}$ \\
\hline
\end{tabular}

${ }^{\mathrm{z}}$ Anthocyanins were obtained in the positive ion mode $\left([\mathrm{M}-\mathrm{H}]^{+}\right)$, other phenolic groups in negative ion mode $\left([\mathrm{M}-\mathrm{H}]^{-}\right)$.

${ }^{y}$ Plant part (in which individual compound was determined): $\mathrm{P}=$ petals; $\mathrm{L}=$ leaves; $\mathrm{PL}=$ petals and leaves.

HHDP $=$ hexahydroxydiphenoyl.

K-rhamnoside, K-glucoside, K-glucuronide, and K-galactoside) in addition to an abundance of species/cultivar specific flavonols was confirmed (Table 3; content levels of major flavonols are represented) in rose petals comparable to previous research (Cai et al., 2005; Kumar et al., 2009; Mikanagi et al., 2000).

The highest content of total quercetin glycosides was determined in flowers of 'Ulrich Brunner Fils' and the two major quercetin glycosides identified in the petals were Q-arabinofuranoside and Q-galactoside. In other Rosa species and cultivars, the abundance of specific quercetin glycosides varied greatly; Q-glucoside was the major quercetin in petals of $R$. canina, $R$. sempervirens, and $R$. rubiginosa, and Q-rhamnoside in petals of R. glauca. Other authors similarly report high levels of quercetin glucoside, arabinoside, rhamnoside, and other glycosides in

Table 3. Flavonols in petals of Rosa species and cultivars.

\begin{tabular}{|c|c|c|c|c|c|c|c|}
\hline \multirow[b]{3}{*}{ Flavonol $^{\mathrm{z}}$} & \multicolumn{7}{|c|}{ Rosa species/cultivar } \\
\hline & R. canina & R. glauca & R. sempervirens & R. rubiginosa & $\begin{array}{c}\text { Rosarium } \\
\text { Uetersen }\end{array}$ & $\begin{array}{l}\text { Ulrich Brunner } \\
\text { Fils }\end{array}$ & Schwanensee \\
\hline & \multicolumn{7}{|c|}{$\left[\right.$ mean \pm SE $\left.\left(\mu \mathrm{g} \cdot \mathrm{g}^{-1} \mathrm{FW}\right)\right]$} \\
\hline 2 & $629.0 \pm 9.7 \mathrm{~d}$ & $259.4 \pm 3.6 \mathrm{~b}$ & $372.8 \pm 7.1 \mathrm{c}$ & $775.0 \pm 12.9 \mathrm{e}$ & $12.6 \pm 0.4 \mathrm{a}$ & $846.8 \pm 44.2 \mathrm{f}$ & $353.9 \pm 1.5 \mathrm{c}$ \\
\hline 3 & $309.4 \pm 7.2 \mathrm{c}$ & $92.5 \pm 1.8 b$ & - & - & $5.5 \pm 0.2 \mathrm{a}$ & $93.1 \pm 1.9 \mathrm{~b}$ & - \\
\hline 4 & $115.5 \pm 0.8 \mathrm{a}$ & $178.0 \pm 2.2 \mathrm{a}$ & $112.9 \pm 1.2 \mathrm{a}$ & - & - & $1279.7 \pm 47.4 \mathrm{c}$ & $906.3 \pm 22.7 b$ \\
\hline 6 & $17.0 \pm 0.9 \mathrm{a}$ & - & $16.1 \pm 0.6 \mathrm{a}$ & $112.4 \pm 5.3 \mathrm{c}$ & - & $139.9 \pm 5.8 \mathrm{~d}$ & $69.5 \pm 1.5 \mathrm{~b}$ \\
\hline 7 & $438.7 \pm 5.0 \mathrm{e}$ & $573.8 \pm 16.3 \mathrm{f}$ & $131.7 \pm 9.7 b$ & $302.8 \pm 3.7 \mathrm{c}$ & $37.9 \pm 1.7 \mathrm{a}$ & $455.4 \pm 7.8 \mathrm{e}$ & $410.7 \pm 5.2 \mathrm{~d}$ \\
\hline 8 & $333.8 \pm 3.8 \mathrm{~d}$ & $126.9 \pm 0.6 \mathrm{~b}$ & - & $51.4 \pm 1.7 \mathrm{a}$ & $217.3 \pm 7.7 \mathrm{c}$ & - & - \\
\hline 9 & $273.6 \pm 4.9 \mathrm{c}$ & $249.6 \pm 1.3 b$ & $407.6 \pm 1.7 \mathrm{~d}$ & $521.9 \pm 10.4 \mathrm{f}$ & $123.9 \pm 6.1 \mathrm{a}$ & $113.9 \pm 3.3 \mathrm{a}$ & $439.0 \pm 5.8 \mathrm{e}$ \\
\hline 10 & $273.5 \pm 1.8 \mathrm{c}$ & $40.8 \pm 0.5 \mathrm{a}$ & $2607.6 \pm 27.7 \mathrm{f}$ & $2463.0 \pm 14.3 \mathrm{e}$ & $42.3 \pm 1.7 \mathrm{a}$ & $130.1 \pm 4.8 b$ & $973.7 \pm 24.4 \mathrm{~d}$ \\
\hline 11 & $182.0 \pm 4.2 \mathrm{c}$ & - & - & - & $13.7 \pm 0.7 \mathrm{a}$ & $22.9 \pm 1.4 \mathrm{~b}$ & - \\
\hline$\%$ Q & $63.7 \pm 0.2 \mathrm{e}$ & $74.1 \pm 0.4 \mathrm{f}$ & $15.0 \pm 0.3 \mathrm{~b}$ & $22.0 \pm 0.1 \mathrm{c}$ & $13.7 \pm 0.2 \mathrm{a}$ & $83.0 \pm 0.8 \mathrm{~g}$ & $43.8 \pm 0.2 \mathrm{~d}$ \\
\hline$\% \mathrm{~K}$ & $36.3 \pm 0.2 \mathrm{c}$ & $25.9 \pm 0.4 b$ & $85.0 \pm 0.3 \mathrm{f}$ & $78.0 \pm 0.1 \mathrm{e}$ & $86.3 \pm 0.2 \mathrm{~g}$ & $17.0 \pm 0.8 \mathrm{a}$ & $56.2 \pm 0.2 \mathrm{~d}$ \\
\hline
\end{tabular}

${ }^{\mathrm{z}}$ Flavonol, quercetin (Q) compounds (1-7): 1 = Q-3-rutinoside, 2 = Q-3-glucoside, 3 = Q-3-glucuronide, 4 = Q-3-arabinofuranoside, 5 = Q-3galactoside, $6=\mathrm{Q}$-3-xyloside, $7=\mathrm{Q}$-3-rhamnoside; kaempferol $(\mathrm{K})$ compounds $(8-12)$ : $8=\mathrm{K}$-di-hexoside, $9=\mathrm{K}$-3-rhamnoside, $10=\mathrm{K}$-3glucoside, $11=\mathrm{K}$-3-glucuronide, $12=\mathrm{K}$-3-galactoside; total $\mathrm{Q}=$ sum of quercetin compounds; total $\mathrm{K}=$ sum of kaempferol compounds; $\% \mathrm{Q}=$ percent of total quercetin compounds among flavonols; $\% \mathrm{~K}=$ percent of total kaempferol compounds among flavonols, $-=$ compound not present in samples.

${ }^{\mathrm{y}}$ Different letters $(\mathrm{a}-\mathrm{g})$ within individual phenolic compound denote statistically significant differences among Rosa species and cultivars by Duncan's multiple range test at $P<0.05$.

$\mathrm{FW}=$ fresh weight. 
petals of different rose species (Barros et al., 2013; Kumar et al., 2009; Schieber et al., 2005).

Based on their fragmentation pattern and ultraviolet spectral data, 17 compounds have been tentatively identified as kaempferol glycosides in rose petals (Table 2). Most species contained high levels of K-glucoside, which is in accordance with the results of Schieber et al. (2005) who investigated phenolic compounds in $R$. damascena flowers and Barros et al. (2013) who identified phenolics in $R$. micrantha flower petals. Several species and cultivars in this study also contained high levels of K-rhamnoside similar to $R$. damascena, $R$. bourboniana, and $R$. brunonii petal profiling reported by Kumar et al. (2009). In quantitative terms, the species with the highest total kaempferol content was $R$. rubiginosa; its petals contained predominantly K-glucoside and K-rhamnoside previously identified in petals of $R$. damascena (Schieber et al., 2005) and $R$. micrantha (Barros et al., 2013). Contrary, the petals of $R$. glauca and 'Rosarium Uetersen' contained less than onetenth the level of total kaempferol glycosides compared with R. rubiginosa.

LEAF PHENOLIC COMPOSITION. Thirty different flavonols have been tentatively identified in leaves of different rose species and cultivars (Table 2). $\mathrm{MS}^{n}$ confirmed the presence of the prevailing quercetin and kaempferol glycosides and in some species/ cultivars also isorhamnetin and myricetin glycosides ( $R$. canina, $R$. sempervirens, and 'Schwanensee'). Porter et al. (2012) correspondingly reported an abundance of kaempferol and quercetin glycosides in leaves of $R$. spinosissima and quercetin glycosides have been detected in leaves of $R$. rugosa (Hashidoko, 1996) and $R$. sericea (Li et al., 2013). Nowak and Gawlik-Dziki (2007) measured total leaf phenolic content, and quercetin and kaempferol levels of different Rosa species including $R$. canina and $R$. rubiginosa but did not study their specific chemical composition. The same applies to research on $R$. sempervirens and $R$. canina leaves by Ghazghazi et al. $(2010,2012)$ and thus the identification of individual components in leaves of selected Rosa species was not comprehensive. In the present research, seven major quercetin glycosides have been identified in rose leaves (Q-arabinofuranoside, Q-galactoside, Q-glucoside, Q-glucuronide, Q-rhamnoside, Q-rutinoside, Q-xyloside). Q-arabinofuranoside, Q-xyloside, and Q-rhamnoside have been determined in all studied species and cultivars. Particularly high levels of the latter were characteristic for $R$. sempervirens and $R$. canina leaves (Table 4 ). Shetty et al. (2011) similarly detected several quercetin and kaempferol glycosides in leaves of $R$. hybrida 'Smart' asserting Q-rutinoside and Q-rhamnoside occurred in highest concentrations.

Three predominant kaempferol glycosides (K-rhamnoside, $\mathrm{K}$-glucuronide, K-glucoside) have been determined in leaves of selected rose species and cultivars (Table 4) in addition to five minor kaempferol compounds (Table 2). Generally, the content of K-glycosides in rose leaves was considerably lower compared with petals and only K-rhamnoside was present in leaves of all studied species and cultivars. Shetty et al. (2011) similarly identified this glycoside as the prevalent kaempferol in $R$. hybrida leaves. The highest content of K-rhamnoside was again determined in $R$. canina leaves, which was correspondingly the species with the highest content of total kaempferol, quercetin, and flavonol glycosides (Fig. 1A). High levels of K-rhamnoside were also detected in 'Ulrich Brunner Fils' and $R$. rubiginosa. The leaves of 'Schwanensee' contained characteristically low levels of total kaempferol and also quercetin glycosides. The percentage of total quercetin and total kaempferol glycosides varied among the studied species and cultivars (Table 4) but generally, quercetin glycosides were the predominant flavonols in most rose leaves, which is in accordance with the research of Nowak and Gawlik-Dziki (2007) on different Rosa species and cultivars.

Table 4. Flavonols in leaves of Rosa species and cultivars.

\begin{tabular}{|c|c|c|c|c|c|c|c|}
\hline \multirow[b]{3}{*}{ Flavonol $^{\mathrm{z}}$} & \multicolumn{7}{|c|}{ Rosa species/cultivar } \\
\hline & R. canina & R. glauca & R. sempervirens & R. rubiginosa & $\begin{array}{l}\text { Rosarium } \\
\text { Uetersen }\end{array}$ & $\begin{array}{l}\text { Ulrich Brunner } \\
\text { Fils }\end{array}$ & Schwanensee \\
\hline & \multicolumn{7}{|c|}{$\left[\right.$ mean \pm SE $\left.\left(\mu \mathrm{g} \cdot \mathrm{g}^{-1} \mathrm{FW}\right)\right]$} \\
\hline 2 & $194.9 \pm 13.3 b$ & - & - & $292.3 \pm 6.8 \mathrm{c}$ & - & $194.4 \pm 17.4 \mathrm{~b}$ & $114.4 \pm 11.4 \mathrm{a}$ \\
\hline 3 & $186.7 \pm 9.9 \mathrm{bc}$ & $54.8 \pm 8.4 \mathrm{a}$ & $191.0 \pm 16.8 \mathrm{c}$ & $325.9 \pm 6.4 \mathrm{~d}$ & $80.9 \pm 5.7 \mathrm{a}$ & $148.7 \pm 8.9 b$ & $88.5 \pm 7.3 \mathrm{a}$ \\
\hline 6 & $37.1 \pm 3.6 \mathrm{~b}$ & - & - & $73.5 \pm 3.6 \mathrm{c}$ & $5.6 \pm 0.4 \mathrm{a}$ & $25.9 \pm 2.9 \mathrm{ab}$ & $172.8 \pm 16.7 \mathrm{~d}$ \\
\hline 7 & $125.9 \pm 14.4 \mathrm{c}$ & $12.2 \pm 1.1 \mathrm{a}$ & $51.9 \pm 6.0 \mathrm{~b}$ & $14.8 \pm 0.6 \mathrm{a}$ & $10.6 \pm 1.4 \mathrm{a}$ & $53.5 \pm 4.6 \mathrm{~b}$ & $48.2 \pm 1.3 \mathrm{~b}$ \\
\hline 8 & $160.3 \pm 36.0 \mathrm{e}$ & $84.9 \pm 3.1 \mathrm{bc}$ & $88.2 \pm 10.4 \mathrm{~cd}$ & $133.0 \pm 5.6 \mathrm{de}$ & $29.8 \pm 5.4 \mathrm{a}$ & $140.5 \pm 13.5 \mathrm{e}$ & $39.2 \pm 3.2 \mathrm{ab}$ \\
\hline 9 & $158.9 \pm 32.4 \mathrm{~b}$ & - & - & $71.0 \pm 2.2 \mathrm{a}$ & $90.4 \pm 8.2 \mathrm{a}$ & - & - \\
\hline 10 & - & - & - & $93.5 \pm 3.3 \mathrm{~b}$ & $16.9 \pm 2.4 \mathrm{a}$ & - & - \\
\hline Total Q & $4201.1 \pm 80.8 \mathrm{e}$ & $1515.4 \pm 149.5 b$ & $3651.3 \pm 168.5 \mathrm{~d}$ & $2449.9 \pm 96.0 \mathrm{c}$ & $1451.1 \pm 125.3 \mathrm{~b}$ & $1699.3 \pm 128.6 \mathrm{~b}$ & $776.8 \pm 77.6 \mathrm{a}$ \\
\hline
\end{tabular}

${ }^{\mathrm{z} F l a v o n o l, ~ q u e r c e t i n}(\mathrm{Q})$ compounds (1-7): 1 = Q-3-arabinofuranoside, 2 = Q-3-galactoside, 3 = Q-3-glucoside, $4=\mathrm{Q}$-3-glucuronide, 5 = Q-3rhamnoside, 6 = Q-3-rutinoside, 7 = Q-3-xyloside; kaempferol $(\mathrm{K})$ compounds (8-10): $8=\mathrm{K}$-3-rhamnoside, $9=\mathrm{K}$-3-glucuronide, $10=\mathrm{K}$-3glucoside; total $\mathrm{Q}=$ sum of quercetin compounds; total $\mathrm{K}=$ sum of kaempferol compounds; \% $\mathrm{Q}=$ percent of total quercetin compounds among flavonols; $\% \mathrm{~K}=$ percent of total kaempferol compounds among flavonols; — = compound not present in samples.

${ }^{\mathrm{y}}$ Different letters (a-e) within individual phenolic compound denote statistically significant differences among Rosa species and cultivars by Duncan's multiple range test at $P<0.05$.

$\mathrm{FW}=$ fresh weight. 

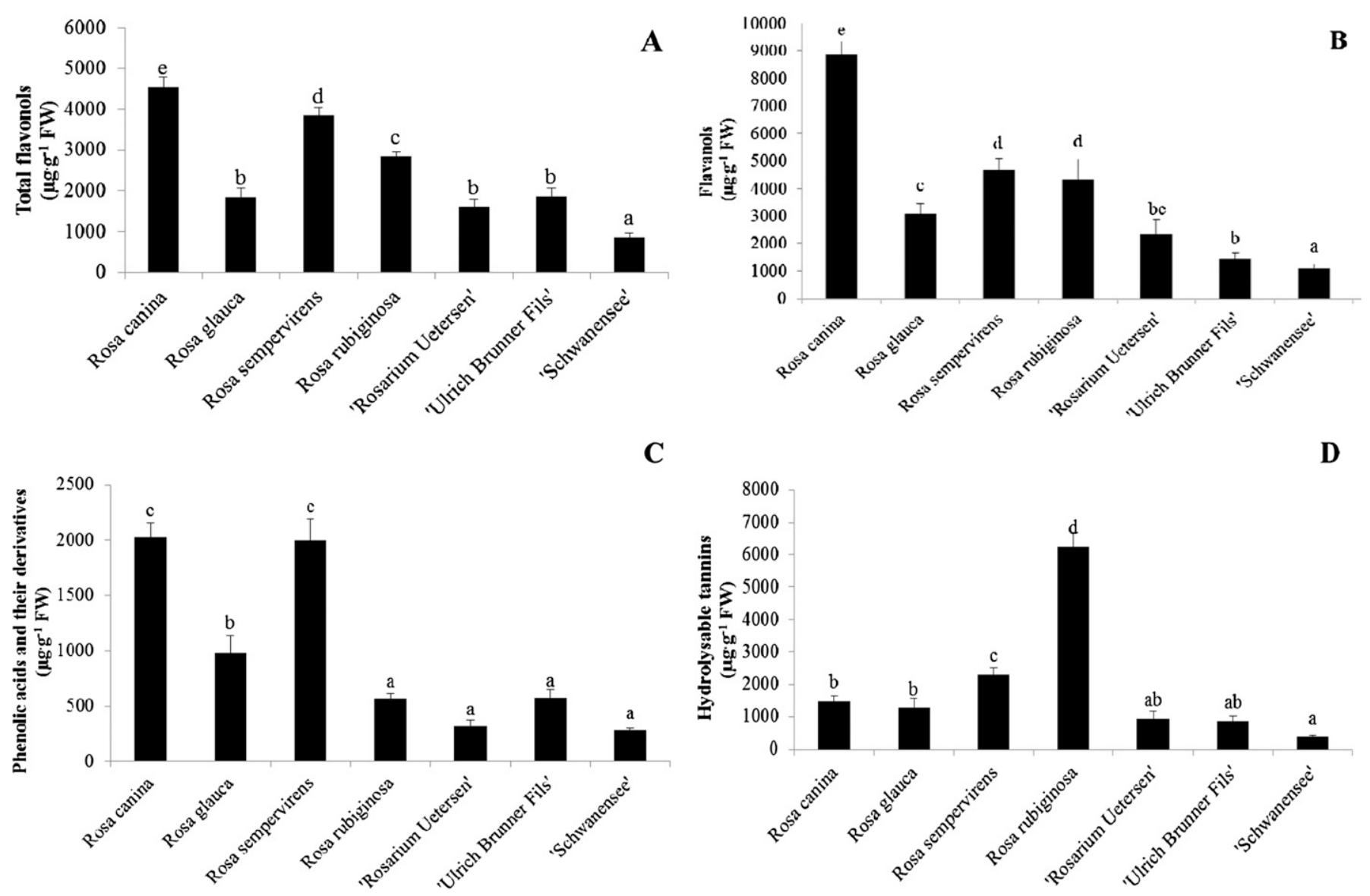

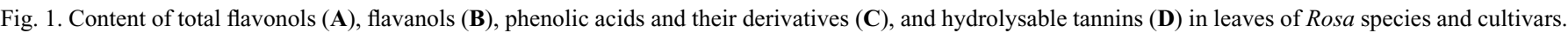
Bars represent SE. Different letters (a-e) within individual phenolic groups denote statistically significant differences among Rosa species and cultivars by Duncan's multiple range test at $P<0.05$.

In addition to flavonols, an abundance of flavanols, phenolic acids, and their derivatives and hydrolysable tannins were determined in leaves of selected Rosa species and cultivars using $\mathrm{MS}^{n}$ (Table 2). Rosaceae can generally be characterized as a family rich in catechin and proanthocyanidin secondary metabolites (Hoffmann et al., 2012). From the group of flavanols, catechin was detected in all studied species and cultivars (Table 5) with the highest content measured in leaves of $R$. canina and the lowest in leaves of 'Schwanensee'. Oppositely, epicatechin could only be identified in 'Schwanensee' leaves. Catechin and epicatechin have previously been determined in extracts of $R$. damascena leaves and different organs of R. rugosa (Hashidoko, 1996). High levels of catechin were recently also quantified in root tips of $R$. Xhybrida (Hoffmann et al., 2012) and in R. micrantha flowers (Barros et al., 2013). According to Baydar and Baydar (2013), catechin and epicatechin represent the most important phenolic constituents of $R$. damascena leaves. $R$. canina leaves contained several procyanidin di- and trimers, and in $R$. canina, $R$. glauca, and $R$. sempervirens, procyanidin tetramers have also been

Table 5. Flavanols in leaves of Rosa species and cultivars.

\begin{tabular}{|c|c|c|c|c|c|c|c|}
\hline \multirow[b]{3}{*}{ Flavanol $^{z}$} & \multicolumn{7}{|c|}{ Rosa species/cultivar } \\
\hline & R. canina & R. glauca & R. sempervirens & R. rubiginosa & $\begin{array}{l}\text { Rosarium } \\
\text { Uetersen }\end{array}$ & $\begin{array}{l}\text { Ulrich Brunner } \\
\text { Fils }\end{array}$ & Schwanensee \\
\hline & \multicolumn{7}{|c|}{$\left[\right.$ mean \pm SE $\left.\left(\mu g \cdot g^{-1} F W\right)\right]$} \\
\hline 2 & $1506.2 \pm 70.4 \mathrm{c}$ & $598.6 \pm 61.6 \mathrm{~b}$ & $664.3 \pm 57.9 b$ & $1502.7 \pm 246.8 \mathrm{c}$ & $176.2 \pm 32.8 \mathrm{a}$ & $123.8 \pm 12.5 \mathrm{a}$ & $131.5 \pm 19.8 \mathrm{a}$ \\
\hline 3 & $3534.4 \pm 180.8 \mathrm{e}$ & $750.8 \pm 74.6 \mathrm{ab}$ & $2336.9 \pm 186.8 \mathrm{~d}$ & $1398.3 \pm 224.0 \mathrm{c}$ & $1026.5 \pm 209.3 \mathrm{bc}$ & $697.2 \pm 70.5 \mathrm{ab}$ & $386.4 \pm 58.2 \mathrm{a}$ \\
\hline 4 & $171.8 \pm 14.3 \mathrm{a}$ & $151.5 \pm 21.0 \mathrm{a}$ & $196.0 \pm 18.1 \mathrm{a}$ & - & - & - & - \\
\hline
\end{tabular}

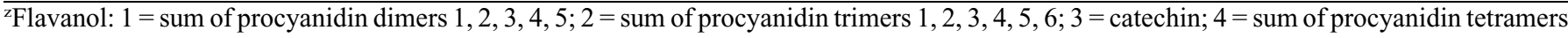
1,$2 ; 5=$ epicatechin; - = compound not present in samples.

${ }^{\mathrm{y}}$ Different letters (a-e) within specific groups of phenolic compounds denote statistically significant differences among Rosa species and cultivars by Duncan's multiple range test at $P<0.05$.

$\mathrm{FW}=$ fresh weight. 
determined. Generally, the rose species in this study contained significantly higher levels of procyanidins and were also richer in total flavanol content compared with the studied cultivars (Table 5; Fig. 1B).

Similar to the flavanol content, diversity and content of phenolic acid (and their derivatives) varied significantly among analyzed species and cultivars (Table 6; Fig. 1C). Cis- and trans-5-caffeoylquinic acid (chlorogenic acid) have been determined in all studied species and cultivars. Shetty et al. (2011) also detected chlorogenic, neochlorogenic, and an unknown phenolic acid in leaves of $R$. hybrida 'Smart' and reported that chlorogenic acid was the most abundant phenolic acid present. Comparatively, this is in accordance with our results because cis-5-caffeoylquinic acid content was highest among all phenolic acids in $R$. canina, $R$. glauca, $R$. rubiginosa, and 'Rosarium Uetersen' leaves; in 'Ulrich Brunner Fils', the predominant phenolic acid was 3-caffeoylquinic acid (neochlorogenic acid). In contrast, in leaves of $R$. sempervirens, ellagic acid was the main phenolic acid constituent and 'Schwanensee' was characterized by high content levels of ellagic acid pentosides.

More than eight minor phenolic acids were tentatively identified in analyzed rose leaves (Table 2). Similarly, Baydar and Baydar (2013) also report low levels of different phenolic acids such as caffeic, chlorogenic, $p$-coumaric, ferulic, and gallic acids in leaves of $R$. damascena.

Twenty hydrolysable tannins have been tentatively identified in rose leaves (Table 2). Despite the research of Miyasaki et al. (2013) who reported ellagic acid as the most important active compound of $R$. rugosa extracts, free ellagic acid was only identified in leaves of $R$. sempervirens, $R$. glauca, and 'Rosarium Uetersen' (Table 6). In leaves of the latter two, it did not represent the major constituent of their leaves. However, numerous conjugated forms and isomers of ellagic acid have been determined in Rosa leaves in the present study, many reported for the first time (Tables 2 and 7). Most importantly, hydrolysable tannins (ellagitannins) have been determined in leaves of selected Rosa species and cultivars consisting of one or more HHDP moieties esterified to a polyol, usually glucose (Haslam, 1996; Koponen et al., 2007). They are important in plant physiology because they provide protection against microbial decay. This ability is linked to their characteristic feature to form strong complexes with proteins and polysaccharides and consequently inhibiting microbial growth (AscacioValdés et al., 2011). Ellagitannins are widely distributed in the Hamamelidae, Dilleniidae, and Rosidae and have frequently been used as chemotaxonomic markers (Haslam, 1996). As a result of their strong antioxidant properties, they are also important in the human diet, especially in the prevention of degenerative diseases (Ascacio-Valdés et al., 2011; Haslam, 1996; Sroka, 2005). The species with the highest total hydrolysable tannin content was $R$. rubiginosa (Fig. 1D), in which the highest levels of HHDP digalloyl glucose isomers, galloyl bis HHDP glucose and trigalloyl HHDP hexose, have been measured. Along with HHDP digalloyl glucose, also di-HHDP glucose isomers and vescalagin isomers have been determined in all studied species and cultivars. The latter was highest in 'Rosarium Uetersen'. The lowest total hydrolysable tannin content was determined in 'Schwanensee'.

Multivariate statistical analysis clustered the analyzed rose species and cultivars into three distinct groups (Fig. 2). Leaf phenolic profile was the principal classification factor and $R$. canina stood out as the species with the highest content and abundance of most phenolic compounds. This is in accordance with the reports of Nowak and Gawlik-Dziki (2007) who also measured highest levels of phenolics in different $R$. canina cultivars. $R$. sempervirens and $R$. rubiginosa represented the second group based on their high content of free and conjugated forms of ellagic acid, flavanols, and phenolic acids and were thus closest to $R$. canina. $R$. glauca was the most

Table 6. Phenolic acids and their derivatives in leaves of Rosa species and cultivars.

\begin{tabular}{|c|c|c|c|c|c|c|c|}
\hline \multirow{3}{*}{$\begin{array}{l}\text { Phenolic acids } \\
\text { and their } \\
\text { derivatives }^{\mathrm{z}}\end{array}$} & \multicolumn{7}{|c|}{ Rosa species/cultivar } \\
\hline & R. canina & R. glauca & R. sempervirens & R. rubiginosa & $\begin{array}{l}\text { Rosarium } \\
\text { Uetersen }\end{array}$ & $\begin{array}{l}\text { Ulrich Brunner } \\
\text { Fils }\end{array}$ & Schwanensee \\
\hline & \multicolumn{7}{|c|}{$\left[\right.$ mean $\left.\pm \mathrm{sE}\left(\mu \mathrm{g} \cdot \mathrm{g}^{-1} \mathrm{FW}\right)\right]$} \\
\hline 2 & - & - & - & - & $58.4 \pm 15.0 \mathrm{~b}$ & - & $28.3 \pm 2.4 \mathrm{a}$ \\
\hline 3 & $473.0 \pm 46.2 \mathrm{c}^{\mathrm{y}}$ & $182.9 \pm 31.4 \mathrm{a}$ & $433.6 \pm 37.5 \mathrm{c}$ & $154.3 \pm 11.0 \mathrm{a}$ & - & $306.1 \pm 53.5 \mathrm{~b}$ & - \\
\hline 4 & $24.5 \pm 2.4$ & - & - & - & - & - & - \\
\hline 6 & $50.0 \pm 4.1 \mathrm{~d}$ & $14.2 \pm 2.8 \mathrm{~b}$ & $29.6 \pm 4.5 \mathrm{c}$ & & & & $1.1 \pm 0.1 \mathrm{a}$ \\
\hline 7 & - & - & $82.2 \pm 12.5 \mathrm{~b}$ & - & - & $25.3 \pm 2.5 \mathrm{a}$ & $20.5 \pm 2.5 \mathrm{a}$ \\
\hline 8 & $97.3 \pm 8.1 \mathrm{~b}$ & $108.8 \pm 18.2 \mathrm{~b}$ & $105.0 \pm 8.4 \mathrm{~b}$ & $97.7 \pm 5.7 b$ & $26.3 \pm 5.0 \mathrm{a}$ & $38.8 \pm 5.5 \mathrm{a}$ & $13.9 \pm 1.8 \mathrm{a}$ \\
\hline 9 & $6.0 \pm 0.3 \mathrm{a}$ & $9.0 \pm 1.5 \mathrm{~b}$ & $17.1 \pm 1.1 \mathrm{c}$ & $11.2 \pm 0.6 \mathrm{~b}$ & $4.4 \pm 1.0 \mathrm{a}$ & - & $8.9 \pm 0.9 b$ \\
\hline 10 & $68.2 \pm 8.7 \mathrm{c}$ & $23.5 \pm 7.0 \mathrm{~b}$ & $6.9 \pm 1.4 \mathrm{ab}$ & $7.0 \pm 0.6 \mathrm{ab}$ & $24.5 \pm 7.8 b$ & - & $3.3 \pm 0.5 \mathrm{a}$ \\
\hline 11 & - & - & - & - & - & - & $20.8 \pm 3.1$ \\
\hline
\end{tabular}

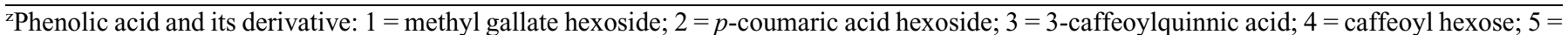
cis-5-caffeoylquinnic acid; $6=4$-caffeoylquinnic acid; $7=$ sinapic acid hexoside; $8=$ trans-5-caffeoylquinnic acid; $9=c i s-5$ - $O$ - $p$ coumaroylquinnic acid; $10=$ trans $-5-O-p$-coumaroylquinnic acid; $11=$ ellagic acid hexoside; $12=$ sum of ellagic acid pentoside 1,$2 ; 13=$ ellagic acid.; $-=$ compound not present in samples.

${ }^{\mathrm{y}}$ Different letters $(\mathrm{a}-\mathrm{c})$ within individual phenolic compound denote statistically significant differences among Rosa species and cultivars by Duncan's multiple range test at $P<0.05$.

$\mathrm{FW}=$ fresh weight. 
Table 7. Hydrolysable tannins in leaves of Rosa species and cultivars.

\begin{tabular}{|c|c|c|c|c|c|c|c|}
\hline \multirow{3}{*}{$\begin{array}{l}\text { Hydrolysable } \\
\text { tannins }\end{array}$} & \multicolumn{7}{|c|}{ Rosa species/cultivar } \\
\hline & R. canina & R. glauca & R. sempervirens & R. rubiginosa & $\begin{array}{l}\text { Rosarium } \\
\text { Uetersen }\end{array}$ & $\begin{array}{l}\text { Ulrich Brunner } \\
\text { Fils }\end{array}$ & Schwanensee \\
\hline & \multicolumn{7}{|c|}{$\left[\right.$ mean $\left.\pm \mathrm{SE}\left(\mu \mathrm{g} \cdot \mathrm{g}^{-1} \mathrm{FW}\right)\right]$} \\
\hline 2 & $266.3 \pm 18.1 \mathrm{~d}$ & $197.0 \pm 46.7 \mathrm{bcd}$ & $210.1 \pm 27.0 \mathrm{~cd}$ & $692.0 \pm 44.2 \mathrm{e}$ & $110.8 \pm 19.0 \mathrm{ab}$ & $154.1 \pm 14.4 \mathrm{bc}$ & $41.0 \pm 3.4 \mathrm{a}$ \\
\hline 3 & $289.2 \pm 38.0 \mathrm{~b}$ & $288.6 \pm 75.9 \mathrm{~b}$ & $66.5 \pm 9.7 \mathrm{a}$ & $117.3 \pm 6.4 \mathrm{a}$ & $324.9 \pm 91.5 b$ & $97.9 \pm 26.8 \mathrm{a}$ & $20.1 \pm 2.1 \mathrm{a}$ \\
\hline 4 & $92.3 \pm 9.8 \mathrm{ab}$ & $171.5 \pm 40.9 \mathrm{c}$ & - & $527.7 \pm 21.8 \mathrm{~d}$ & $121.8 \pm 29.4 \mathrm{bc}$ & $35.4 \pm 7.4 \mathrm{a}$ & $32.6 \pm 6.1 \mathrm{a}$ \\
\hline 6 & $354.8 \pm 22.9 \mathrm{~b}$ & $172.8 \pm 30.6 \mathrm{a}$ & $395.4 \pm 41.8 b$ & $655.0 \pm 29.4 \mathrm{c}$ & $161.8 \pm 28.0 \mathrm{a}$ & $153.7 \pm 26.5 \mathrm{a}$ & $115.2 \pm 14.5 \mathrm{a}$ \\
\hline 7 & - & - & $695.1 \pm 53.0 \mathrm{~b}$ & $313.5 \pm 20.0 \mathrm{a}$ & - & - & - \\
\hline 8 & - & - & - & $328.8 \pm 21.3 \mathrm{~b}$ & - & $95.3 \pm 13.7 \mathrm{a}$ & - \\
\hline 9 & - & $38.5 \pm 5.4 \mathrm{a}$ & $114.9 \pm 8.0 \mathrm{~b}$ & $138.4 \pm 7.3 \mathrm{c}$ & $37.2 \pm 9.4 \mathrm{a}$ & - & - \\
\hline 10 & - & - & - & - & - & $31.0 \pm 7.4$ & - \\
\hline
\end{tabular}

${ }^{\mathrm{z}}$ Hydrolysable tannin: 1 = sum of di-HHDP glucose 1, 2; $2=$ sum of HHDP digalloyl glucose isomer 1, 2, 3; 3 = sum of vescalagin isomer 1,2,3, 4; 4 = galloyl bis HHDP glucose; $5=$ sum of trigalloyl HHDP glucose 1, 2; $6=$ galloyl quinic acid; $7=$ digalloyl quinic acid; $8=$ sum of digalloyl glucose isomer $1,2,3 ; 9=$ sum of trigalloyl hexose 1,$2 ; 10=$ digalloyl pentose; - = compound not present in samples.

y Different letters $(\mathrm{a}-\mathrm{e})$ within individual phenolic compound denote statistically significant differences among Rosa species and cultivars by Duncan's multiple range test at $P<0.05$.

$\mathrm{FW}=$ fresh weight; HHDP $=$ hexahydroxydiphenoyl.

distinct of all species analyzed and grouped in the third cluster along with rose cultivars. However, 'Schwanensee' appeared most dissimilar of all cultivars analyzed as a result of low levels of phenolic constituents measured in its leaves (Tables 4 to 7 ). This could potentially be linked to its known susceptibility to diseases because phenolic composition and their antioxidant effects reportedly play a role in plants' defense against various stressors (Dixon and Paiva, 1995; Osbourn, 1996; Shetty et al., 2011; Sroka, 2005).

It seems that species are more suitable as a potential source of leaf phenols with antioxidative activity. Traditional practice of $R$. canina selective use for medicinal purposes also appears

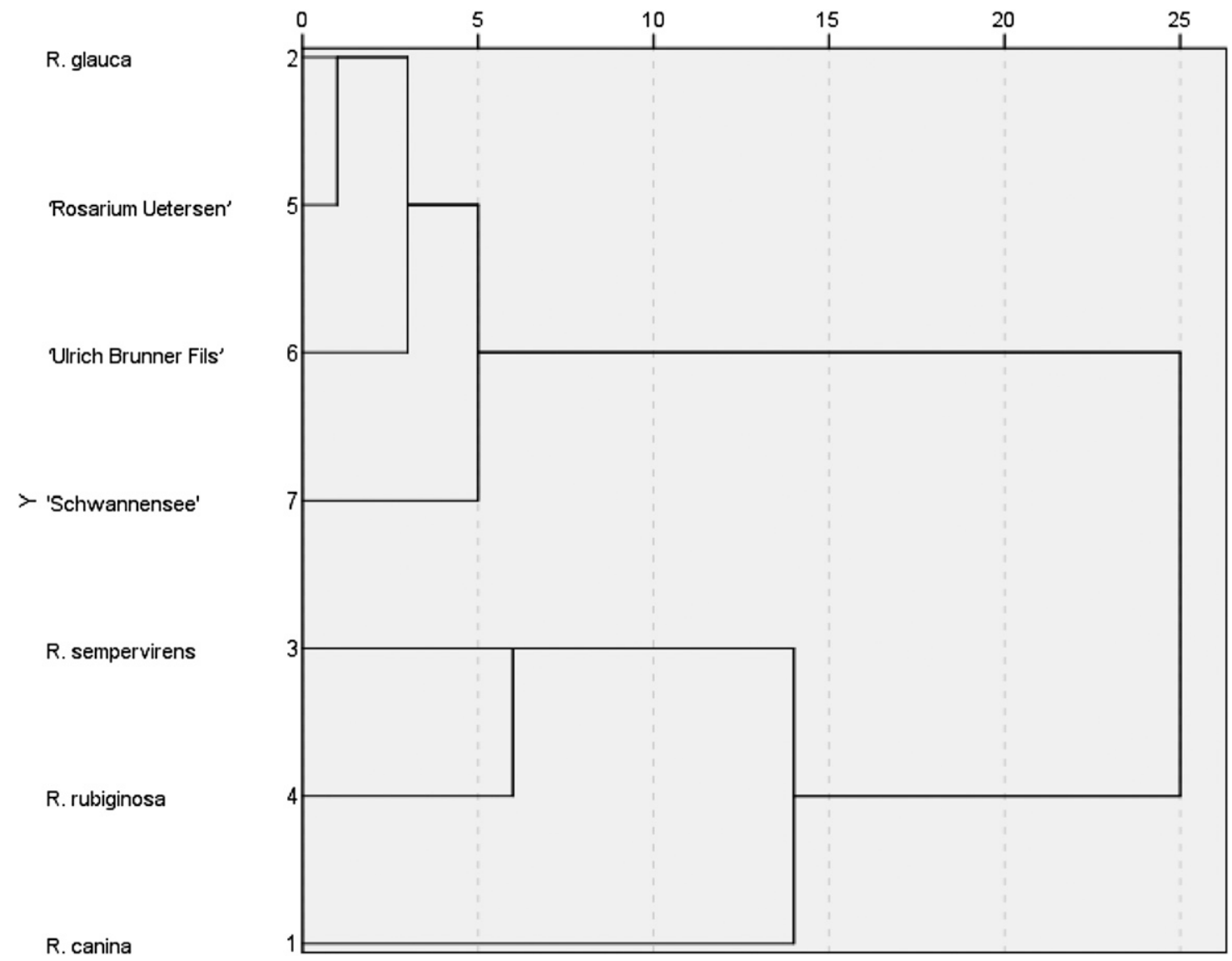

Fig. 2. Dendrogram of Rosa species and cultivars using Ward's method based on square Euclidian distance combining biochemical data on petal and leaf phenolic composition. 
scientifically justified because it contained significantly more phenolic antioxidants compared with other naturally occurring rose species of the region. Moreover, because specific phenolic compounds display different biological functions in plants themselves, the data on phenolic content in rose species and cultivars may be important in breeding for further research of resistance and susceptibility to plant disease.

\section{Literature Cited}

Ascacio-Valdés, J.A., J.J. Buenrostro-Figueroa, A. Aguilera-Carbo, A. Prado-Barragán, R. Rodríguez-Herrera, and C.N. Aguilar. 2011. Ellagitannins: Biosynthesis, biodegradation and biological properties. J. Medicinal Plants Res. 5:4696-4703.

Barros, L., C.T. Alves, M. Duenas, S. Silva, R. Oliveira, A.M. Carvalho, M. Henriques, C. Santos-Buelga, and I.C.F.R. Ferreira. 2013. Characterization of phenolic compounds in wild medicinal flowers from Portugal by HPLC-DAD-ESI/MS and evaluation of antifungal properties. Ind. Crops Prod 44:104-110.

Baydar, N.G. and H. Baydar. 2013. Phenolic compounds, antiradical activity and antioxidant capacity of oil-bearing rose (Rosa damascene Mill.) extracts. Ind. Crops Prod. 41:375-380.

Biolley, J.P., M. Jay, and M.R. Viricel. 1994. Flavonoid diversity and metabolism in 100 Rosa $\times$ hybrida cultivars. Phytochemistry 35:413-419.

Cai, Y.Z., J. Xing, M. Sun, Z.Q. Zhan, and H. Corke. 2005. Phenolic antioxidants (hydrolyzable tannins, flavonols, and anthocyanins) identified by LC-ESI-MS and MALDI-QIT-TOF MS from Rosa chinensis flowers. J. Agr. Food Chem. 53:9940-9948.

Coruh, S and S. Ercisli. 2010. Interactions between galling insects and plant total phenolic contents in Rosa canina L. genotypes. Sci. Res. Essays 5:1935-1937.

Dixon, R.A and N.L. Paiva. 1995. Stress-induced phenylpropanoid metabolism. Plant Cell 7:1085-1097.

Eugster, C.H. and E. Märki-Fischer. 1991. The chemistry of rose pigments. Angewandte Chemie Intl. Edition 30:654-672.

Farooq, A., A. Younis, M. Qasim, A. Riaz, S.M. Abbas, and U. Tariq. 2012. Gas chromatography analysis of the absolute rose oil from Rosa damascena landraces and scented rose species from Pakistan. Intl. J. Agr. Biol. 14:713-719.

Fenglin, H., L. Ruili, H. Bao, and M. Liang. 2004. Free radical scavenging activity of extracts prepared from fresh leaves of selected Chinese medicinal plants. Fitoterapia 75:14-23.

Ghazghazi, H., M.G. Miguel, B. Hasnaoui, H. Sebei, A.C. Figueiredo, L.G. Pedro, and J.G. Barroso. 2012. Leaf essential oil, leaf methanolic extract and rose hips carotenoids from Rosa sempervirens L. growing in north of Tunisia and their antioxidant activities. J. Medicinal Plants Res. 6:574-579.

Ghazghazi, H., M.G. Miguel, B. Hasnaoui, H. Sebei, M. Ksontini, A.C. Figueiredo, L.G. Pedro, and J.G. Barroso. 2010. Phenols, essential oils and carotenoids of Rosa canina from Tunisia and their antioxidant activities. African J. Biotechnol. 9:2709-2716.

Hashidoko, Y. 1996. The phytochemistry of Rosa rugosa. Phytochemistry 43:535-549.

Haslam, E. 1996. Natural polyphenols (vegetable tannins) as drugs: Possible modes of action. J. Natural Prod. 59:205-215.

Hoffmann, T., R. Friedlhuber, C. Steinhauser, I. Tittel, K. Skowranek, W. Schwab, and T.C. Fischer. 2012. Histochemical screening, metabolite profiling and expression analysis reveal Rosaceae roots as the site of flavan-3-ol biosynthesis. Plant Biol. 14:33-40.

Hvattum, E. 2002. Determination of phenolic compounds in rose hip (Rosa canina) using liquid chromatography coupled to electrospray ionisation tandem mass spectrometry and diode-array detection. Rapid Commun. Mass Spectrometry 16:655-662.

Koponen, J.M., A.M. Happonen, P.H. Mattila, and A.R Törrönen. 2007. Contents of anthocyanins and ellagitannins in selected foods consumed in Finland. J. Agr. Food Chem. 55:1612-1619.
Kumar, N., P. Bhandari, B. Singh, and S.S. Bari. 2009. Antioxidant activity and ultra-performance LC-electrospray ionizationquadrupole time-of-flight mass spectrometry for phenolics-based fingerprinting of rose species: Rosa damascena, Rosa bourboniana and Rosa brunonii. Food Chem. Toxicol. 47:361-367.

Kumar, N., P. Bhandari, B. Singh, A.P. Gupta, and V.K. Kaul. 2008. Reversed phase-HPLC for rapid determination of polyphenols in flowers of rose species. J. Separation Sci. 31:262-267.

Lancaster, J.E., C.E. Lister, P.F. Reay, and C.M. Triggs. 1997. Influence of pigment composition on skin color in a wide range of fruit and vegetables. J. Amer. Soc. Hort. Sci 122:594-598.

Li, J.R., J. Liu, D.H. He, H.X. Xu, L.S. Ding, W.K. Bao, Z.Q. Zhou, and Y. Zhou. 2013. Three new phenolic compounds from the leaves of Rosa sericea. Fitoterapia 84:332-337.

Martincic, A., T. Wraber, N. Jogan, V. Ravnik, A. Podobnik, B. Turk, and B. Vres. 1999. Mala flora Slovenije. Tehniska zalozba Slovenije, Ljubljana, Slovenia.

Mikanagi, Y., N. Saito, M. Yokoi, and F. Tatsuzawa. 2000. Anthocyanins in flowers of genus Rosa, sections Cinnamomeae (=Rosa), Chinenses, Gallicanae and some modern garden roses. Biochem. Systematics Ecol. 28:887-902.

Mikanagi, Y., M. Yokoi, Y. Ueda, and N. Saito. 1995. Flower flavonol and anthocyanin distribution in subgenus Rosa. Biochemical Systematics Ecol. 23:183-200.

Miyasaki, Y., J.D. Rabenstein, J. Rhea, M.-L. Crouch, U.M. Mocek, P. Emmett Kittell, M.A. Morgan, W.S. Nichols, M.M. van Benschoten, W.D. Hardy, and G.Y. Liu. 2013. Isolation and characterization of antimicrobial compounds in plant extracts against multidrug-resistant Acinetobacter baumannii. PLOS One $8: 1-8$.

Nowak, R. and Gawlik-Dziki. 2007. Polyphenols of Rosa L. leaves extracts and their radical scavenging activity. Zeitschrift für Naturforschung C 62:32-38.

Osbourn, A.E. 1996. Preformed antimicrobial compounds and plant defense against fungal attack. Plant Cell 8:1821-1831.

Porter, E.A., A. van den Bos, G.C. Kite, N.C. Veitch, and M.S.J. Simmonds. 2012. Flavonol glycosides acylated with 3-hydroxy-3methylglutaric acid as systematic characters in Rosa. Phytochemistry 81:90-96.

Roman, I., A. Stănilă, and S. Stănilă. 2013. Bioactive compounds and antioxidant activity of Rosa canina L. biotypes from spontaneous flora of Transylvania. Chem. Central J. 7:73-82.

Schieber, A., K. Mihalev, N. Berardini, P. Mollov, and R. Carle. 2005. Flavonol glycosides from distilled petals of Rosa damascena Mill. Zeitschrift für Naturforschung C 60:379-384.

Schmitzer, V., R. Veberic, G. Osterc, and F. Stampar. 2010. Color and phenolic content changes during flower development in groundcover rose. J. Amer. Soc. Hort. Sci. 135:195-202.

Schmitzer, V., R. Veberic, and F. Stampar. 2012. Prohexadione-Ca application modifies flavonoid composition and color characteristics of rose (Rosa hybrida L.) flowers. Scientia Hort. 146: 14-20.

Shetty, R., X. Fretté, B. Jensen, N.P. Shetty, J.D. Jensen, H.J. Jørgensen, M.A. Newman, and L.P. Christensen. 2011. Siliconinduced changes in antifungal phenolic acids, flavonoids, and key phenylpropanoid pathway genes during the interaction between miniature roses and the biotrophic pathogen Podosphaera pannosa. Plant Physiol. 157:2194-2205.

Sroka, Z. 2005. Antioxidative and antiradical properties of plant phenolics. Zeitschrift für Naturforschung C 60:833-843.

Tatsuzawa, F., N. Saito, K. Toki, K. Shinoda, and T. Honda. 2012. Flower colors and their anthocyanins in Matthiola incana cultivars (Brassicaceae). J. Jpn. Soc. Hort. Sci. 8:91-100.

Wang, S.Y., W. Zheng, and G.J. Galletta. 2002. Cultural system affects fruit quality and antioxidant capacity in strawberries. J. Agr. Food Chem. 50:6534-6542. 